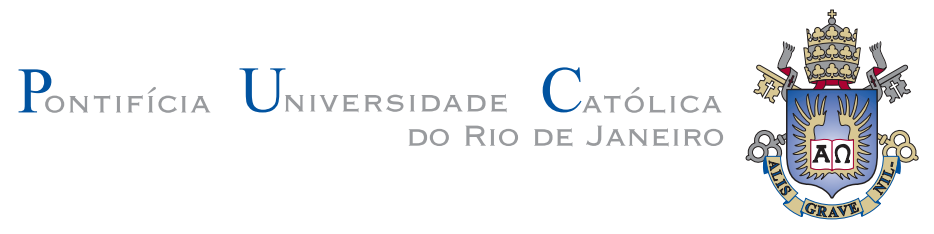

Rodolfo Saboia Lima de Souza

Controle de Potência em Sistemas de Comunicações

Móveis Celulares

Tese de Doutorado

Tese apresentada como requisito parcial para obtenção do título de Doutor pelo Programa de PósGraduação em Engenharia Elétrica da PUC-Rio.

Orientador: Marco Antônio Grivet Mattoso Maia

Rio de Janeiro

28 de abril de 2003 
Rodolfo Saboia Lima de Souza

\section{Controle de Potência em Sistemas de Comunicações Móveis Celulares}

Tese apresentada como requisito parcial para obtenção do título de Doutor pelo Programa de Pós-Graduação em Engenharia Elétrica da PUC-Rio. Aprovada pela Comissão Examinadora abaixo assinada.

Marco Antônio Grivet Mattoso Maia

Orientador

PUC-Rio

Marco Antônio Grivet Mattoso Maia

PUC-Rio

Luiz Alencar Reis da Silva Mello

PUC-Rio

Oscar Porto

PUC-Rio

Ernesto Leite Pinto

IME

Erasmus Couto Brazil de Miranda

UCP

Ney Augusto Dumont

Coordenador(a) Setorial do Centro Técnico Científico - PUC-Rio 
Todos os direitos reservados. É proibida a reprodução total ou parcial do trabalho sem autorização da universidade, do autor e do orientador.

Rodolfo Saboia Lima de Souza

$\mathrm{O}$ autor é graduado e mestre em engenharia de telecomunicações pela PUC-RIO. Trabalha na mesma instituição como engenheiro de pesquisa, onde realiza trabalhos nas áreas de propagação radioelétrica e redes de comunicações.

Ficha Catalográfica

Souza, Rodolfo Saboia Lima de
Controle de potência em sistemas de
comunicações móveis celulares / Rodolfo Saboia Lima de
Souza; orientador: Marco Antônio Grivet Mattoso Maia. -
Rio de Janeiro : PUC, Departamento de Engenharia
Elétrica, 2003.
103 f. : il. ; 30 cm
Dissertação (mestrado) - Pontifícia Universidade
Católica do Rio de Janeiro, Departamento de Engenharia
Elétrica.
Inclui referências bibliográficas.
1. Engenharia Elétrica - Teses. 2. Controle de
potência. 3. Alocações de recursos. 4. Comunicações
móveis. 5. Sistemas celulares. I. Maia, Marco Antônio
Grivet Mattoso. II. Pontifícia Universidade Católica do Rio
de Janeiro. Departamento de Engenharia Elétrica. III.
Título.

CDD: 621.3 
A Inácio de Loyola, peregrino e pedagogo. 


\section{Agradecimentos}

A minha esposa e filhas, pela paciência e compreensão;

A meus amigos por rezarem por mim;

A meus colegas de trabalho pela ajuda;

Ao PUC-Rio por me permitir enquanto funcionário fazer doutorado;

A Axioma Optmization por emprestar o programa de otimização;

Ao prof. Marco Grivet meu orientador pela enorme participação no trabalho. 


\section{Resumo}

Souza, Rodolfo Saboia Lima. Controle de Potência em Sistemas de Comunicações Móveis Celulares. Rio de Janeiro, 2003. xxxp. Tese de Doutorado - Departamento de Engenharia Elétrica, Pontifícia Universidade Católica do Rio de Janeiro.

Este trabalho examina várias técnicas de alocação de canais, e alocação de potência, baseados no parâmetro relação sinal ruído interferência. Os esquemas de controle de potência que utilizam este parâmetro, são resolvidos a partir da determinação do raio espectral de uma matriz obtida a partir da manipulação da matriz de ganhos de enlace. Foi provado que é possível resolver esta matriz por outro método baseado em determinantes, e também foi mostrado que este método permite se obter rapidamente uma alocação de canais factível. Além disso, várias técnicas de otimização da alocação de potência foram estudadas, ampliando a abordagem para uma visão completa do problema de alocação de potência.

\section{Palavras-chave}

Controle de potência; alocações de recursos; comunicações móveis; sistemas celulares 


\section{Sumário}

1 Introdução

2 Sistemas de Rádio $\quad 15$

2.1. Comunicações de dados 15

2.2. Gerenciamento de recursos de rádio 18

2.2.1. Controle de Potência 19

2.2.2. Controle de taxa de transmissão 20

$\begin{array}{ll}\text { 2.2.3. Controle de admissão } & 21\end{array}$

2.2.4. Controle de Congestionamento 21

2.2.5. Agendamento da Transmissão 22

2.2.6. Controle unificado 23

2.3. Acesso Múltiplo 24

2.4. Paradigmas de sistemas de comunicação 26

$\begin{array}{ll}\text { 2.5. Trabalhos anteriores } & 30\end{array}$

3 Elementos de modelagem para o problema de controle de potência 34

4 Métodos de Solução dos Problemas Apresentados 41

4.1. O Problema da Viabilidade de Compartilhamento de Canais 42

4.1.1. Demonstração do Teorema $2 \quad 47$

4.2. O Problema da Determinação dos Subconjuntos f-viáveis 50

4.3. O problema da limitação de potência 55

4.4. Problemas Baseados em Seleção de Subconjuntos Viáveis 57

4.4.1. O Problema do Número Mínimo de Canais 59

4.4.2 O Problema de Mínima Potência Máxima 59

4.5. Uma Heurística Para Determinação do Número Mínimo de Canais 62

4.6. O Problema de Mínima Interferência Revisitado 66

4.6.1 O Caso da 1-Adjacência $\quad 69$

4.6.2 O Caso da 2-Adjacência 70

4.7. Metáforas Evolucionais para o Problema de Mínima Interferência 72 
5 Resultados numéricos 76

5.1. Cenário $\quad 77$

5.2. Determinação dos conjuntos de enlaces viáveis 79

5.3. Minimização do número de canais, ou da máxima potência 84

5.4. Heurística para determinação do número de canais 87

6 Conclusão 91

6.1. Sumário 91

6.2. Discussão 92

6.3. Sugestões para trabalhos futuros 93

$\begin{array}{ll}\text { Glossário } & 94\end{array}$

Referências Bibliográficas $\quad 95$ 


\section{Lista de figuras}

Figura 2-1 - Gerência de recursos de transmissão 23

Figura 4-1 - Região de solução f-viável 43

Figura 4-2 - Comparação de esforços computacionais 55

Figura 4-3 - Min-max de dimensão $2 \quad 60$

Figura 4-4 - Verificação de e-viabilidade em dimensão 2

Figura 5-1 - Posicionamento de transmissores e receptores no cenário 79

Figura 5-2 - Espalhamento de potência dos conjuntos f-viáveis 83

Figura 5-3 - Efeito do relaxamento da condição de número de canais 86

Figura 5-4 - Efeito do relaxamento da condição de número de canais $2 \quad 87$

Figura 5-5 - Comparação do algoritmo sub-ótimo com o resultado da otimização 


\section{Lista de tabelas}

$\begin{array}{ll}\text { Tabela } 1 \text { Classes de serviço em redes UMTS } & 16\end{array}$

$\begin{array}{ll}\text { Tabela } 2 \text { - Requisitos de QoS para as classes de serviço } & 17\end{array}$

Tabela 3 - Tabela de esforço computacional $\quad 54$

$\begin{array}{ll}\text { Tabela 4- Parâmetros de configuração de cenário } & 78\end{array}$

Tabela 6 - Variação do número de conjuntos e-viáveis com variação da semente

Tabela 7 - Variação do número de conjuntos e-viáveis com a SINR 82

Tabela 8 - Variação do número de conjuntos e-viáveis com a potência de ruído 83

Tabela 9 - Efeito do relaxamento da condição de número de canais 86

Tabela 10 - Efeito do relaxamento da condição de número de canais caso 287 